Article

\title{
Ejin Oasis Land Use and Vegetation Change between 2000 and 2011: The Role of the Ecological Water Diversion Project
}

\section{Xiaoli Hu ${ }^{1,2}$, Ling Lu ${ }^{1, *}$, Xin $\mathrm{Li}^{1,3}$, Jianhua Wang ${ }^{1}$ and Xuegang $\mathrm{Lu}^{4}$}

1 Key Laboratory of Remote Sensing of Gansu Province, Cold and Arid Regions Environmental and Engineering Research Institute, Chinese Academy of Sciences, No. 320 Donggang West Road, Lanzhou 730000, Gansu, China; E-Mails: huxiaoli@1zb.ac.cn (X.H.); lixin@1zb.ac.cn (X.L.); jhwang@1zb.ac.cn (J.W.)

2 University of Chinese Academy of Sciences, No. 19A Yuquan Road, Beijing 100049, China

3 CAS Center for Excellence in Tibetan Plateau Earth Sciences, No. 16 Lincui Road, Chaoyang District, Beijing 100101, China

4 Heihe River Bureau, No. 458 Qingyang Road, Lanzhou 730030, Gansu, China; E-Mail: luxuegang458@hotmail.com

* Author to whom correspondence should be addressed; E-Mail: luling@1zb.ac.cn; Tel.: +86-931-4967-249; Fax: +86-931-4967-250.

Academic Editor: Xiangzheng Deng

Received: 6 May 2015 / Accepted: 6 July 2015 / Published: 13 July 2015

Abstract: Ejin Oasis, located in the lower reaches of the Heihe River Basin (HRB), has experienced severe ecosystem decline between the 1960s and 1990s. In response, the Chinese Government implemented the Ecological Water Diversion Project (EWDP) in 2000. To evaluate the effects of the EWDP, this study monitored changes in land use and vegetation in the Ejin Oasis since 2000 and examined driving factors behind such changes. Results demonstrated that the Ejin Oasis ecosystem generally improved between 2000 and 2011. Water body area significantly increased. Lake area of once dried-up Sogo Nuur increased to $45 \mathrm{~km}^{2}$. Accordingly, vegetation cover restoration has also significantly increased. For example, the Seasonally Integrated Normalized Difference Vegetation Index (SINDVI) has shown that $31.18 \%$ of the entire study area experienced an increase in vegetation area. On the other hand, even though the EWDP has been successful in driving vegetation recovery and lake restoration, farmland reclamation has counteracted such restoration initiatives. Farmland area almost doubled between 2000 and 2011. Thus, farmland expansion management is necessary for the full restoration of the Ejin Oasis 
ecosystems as well as HRB sustainable development. The results of this study can provide a reference for the management of the HRB.

Keywords: land use change; SINDVI; EWDP; change detection; water resource management; sustainable development; Heihe River Basin

\section{Introduction}

Water is fundamental to socioeconomic development and maintaining ecosystem health [1]. As a consequence of increasing human activity in and around sensitive areas of water resources, water is rapidly becoming a scarce resource in many regions of the world. This is especially true for arid inland river basins [1,2] that are vulnerable to imbalances between availability and demand, degradation in surface and groundwater quality, intersectoral competition, and inter-regional and international conflicts [2-5]. Such problems have resulted in potential risks to ecological, economic, and social sustainability in arid regions. Accordingly, new water management strategies are required for arid inland river basins [6].

Land use/cover change (LUCC) as well as changes in vegetation cover are recognized as important indicators of global environmental change and sustainable development [7,8]. Based on the different categories of available remote sensing data, a number of studies have been conducted using various algorithms and methodologies [9-15]. However, given the complexity of components that comprise geographic territories, as well as differences in research purposes, it is difficult to develop a general method to monitor patterns and dynamics of land use/cover and vegetation in different regions around the world. Nevertheless, relevant scientific research into spatiotemporal data applications related to land use/cover and vegetation based on remote sensing and GIS remains important to assess roles of water management strategies and understand regional sustainable development [16,17].

The Heihe River Basin (HRB) is a typical inland river basin in the arid region of northwestern China. Its source originates in the Qilian Mountains in Qinghai Province, which then flows through the Hexi Corridor in Gansu Province before entering the Alxa Plateau located inside the Inner Mongolia Autonomous Region. Heihe River runoff supplies water for agricultural usage and ecosystem stabilization in the middle and lower reaches of the HRB and is highly sensitive to climate change and human activity [18-22]. Since the 1960s, the HRB climate has experienced a prolonged warm-wet period but no strong fluctuations as a result of global warming [21-23]. Human activity has therefore become the dominant driver for runoff changes in this region over the last 60 years. The consumption of runoff from the upper reaches of the HRB greatly increased in the middle reaches due to large-scale expansion of irrigated farmland in the middle reaches. Increased HRB runoff consumption as well as a lack of effective water resource management has led to a sharp decline in downstream flow between the 1960s and 1990s, resulting in a series of eco-environmental privations for the HRB [24-29]. For example, plant cover in the lower reaches has declined dramatically, and a large area of Desert poplar forest area has disappeared as a result [30]. The terminal lakes Gaxun Nuur (West Juyan Lake) and Sogo Nuur (East Juyan Lake) dried-up in 1961 and 1992, respectively [24]. To prevent further ecosystem deterioration and to alleviate conflicts between upstream and downstream consumption demands, 
the Chinese Government implemented the Ecological Water Diversion Project (EWDP) in 2000 [31]. According to the design of this project, the middle reaches should transfer $9.5 \times 10^{8} \mathrm{~m}^{3}$ of water to the lower reaches when the upper reaches discharge $15.8 \times 10^{8} \mathrm{~m}^{3}$ of water during normal years of operation. At the same time, in order to achieve the full recovery of lower reach ecosystems, the implementation of supplemental ecological protection projects has also been recommended within the EWDP framework, such as the construction of artificial canals, the development of forage bases, the building of "living" fences (applying native Desert poplar tree species), and the application of natural vegetation irrigation initiatives.

Questions such as how ecosystems changed in the lower reaches of the HRB after the implementation of the EWDP and whether or not vegetation could be restored are not only the focus of attention of the government, public, and scholars, but are also of great significance to the overall maintenance of sustainable HRB development. Thus, the objectives of this study were to monitor ecological conditions of land use and vegetation changes in the Ejin Oasis of the lower reaches of the HRB after the implementation of the EWDP, and to examine driving factors behind such ecosystem changes. Results from this study could potentially be applied to other inland river basin management initiatives.

\section{Study Area}

The Ejin Oasis is located in the lower reaches of the HRB within the western region of Inner Mongolia, China, between $100^{\circ} 16^{\prime}$ and $101^{\circ} 21^{\prime} \mathrm{E}$ and $41^{\circ} 02^{\prime}$ and $42^{\circ} 30^{\prime} \mathrm{N}$ (Figure 1). The total area of the oasis is $5838.51 \mathrm{~km}^{2}$. The region belongs to an extreme arid climate zone that experiences exceptionally low precipitation and strong evaporation. Mean annual precipitation in the Ejin Oasis is $34.9 \mathrm{~mm}$, and annual potential evaporation is $3653 \mathrm{~mm}$. Additionally, mean annual temperature is $8.9^{\circ} \mathrm{C}$ with a maximum daily temperature of $43.1{ }^{\circ} \mathrm{C}$ (July) and a minimum of $-36.4{ }^{\circ} \mathrm{C}$ (February). Mean annual wind speed is $3.9 \mathrm{~m} / \mathrm{s}$.

Given such low precipitation, the Heihe River is the principal water resource within the study area [32]. The Heihe River enters the lower reaches at the Zhengyixia hydrological station, and then divides into Donghe River and Xihe River branches at the Langxinshan hydrological station. The Donghe River and Xihe Rivers divide into several branches that ultimately flow into Sogo Nuur and Gaxun Nuur, respectively. The Ejin Oasis is primarily situated alongside rivers on the alluvial fan. Vegetation in the region is fragmented and easily disturbed. Desert poplar (populus spp), Salt cedar (Tamarix spp), Russian olive, and Saxaul are the primary vegetation species found in the study area. 


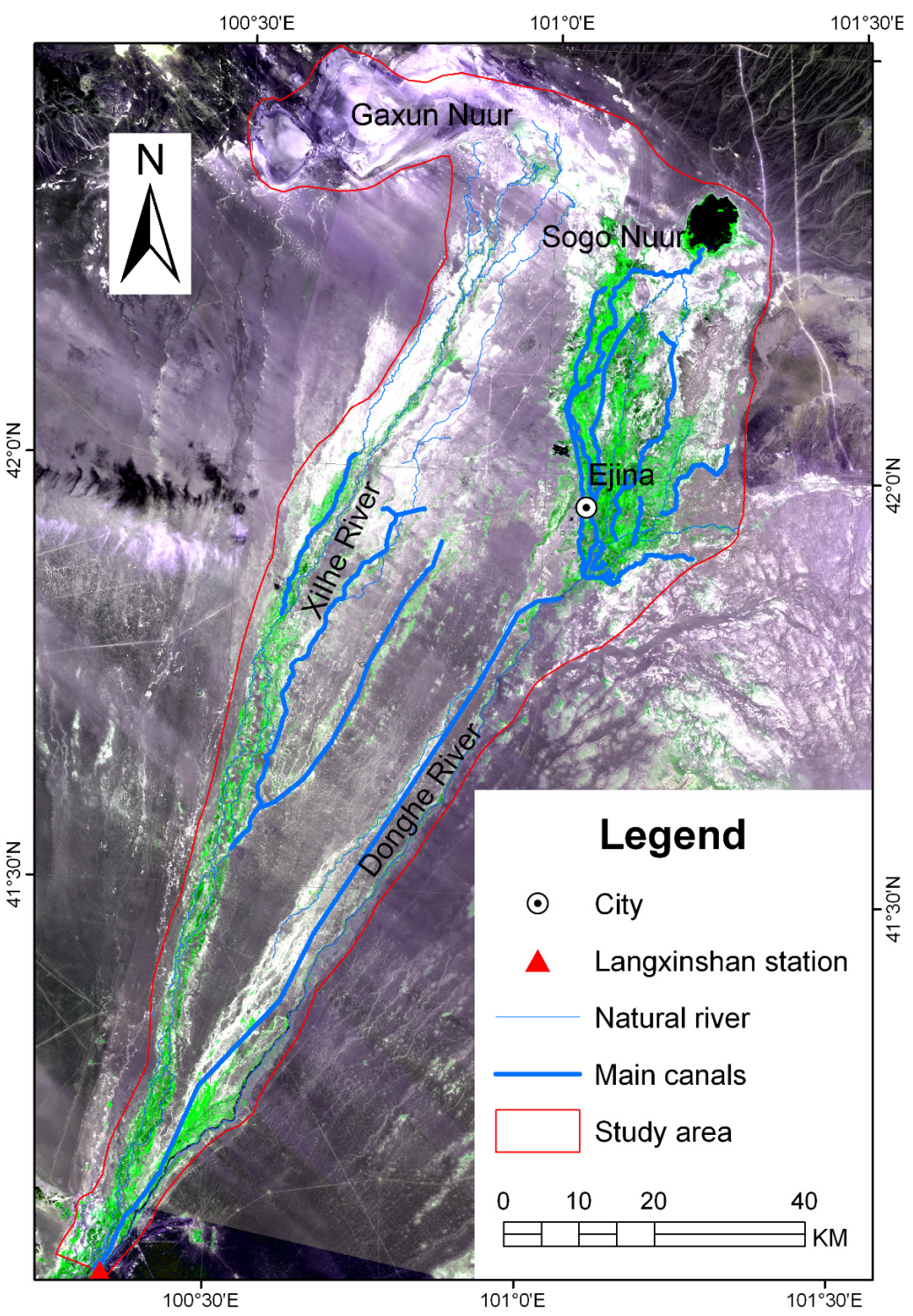

Figure 1. The study area.

\section{Material and Methods}

\subsection{Data}

Remote sensing data has been widely used to monitor land use and vegetation change. High-resolution remote sensing data is the most commonly used data source. This study implemented land use and vegetation change monitoring based primarily on different satellite remote sensing images, i.e., Landsat Thematic Mapper (TM) and Enhanced Thematic Mapper Plus (ETM+) images, Global Inventory Modeling and Mapping Studies (GIMMS) normalized difference vegetation index (NDVI), and Moderate Resolution Imaging Spectroradiometer (MODIS) normalized difference vegetation index (NDVI) data. Landsat TM/ETM+ images were used to monitor changes in land use in the Ejin Oasis while GIMMS NDVI and MODIS NDVI data were used to investigate trends in vegetation change.

Landsat $\mathrm{TM} / \mathrm{ETM}+$ images with a spatial resolution of $30 \mathrm{~m}$ were downloaded from the U.S. Geological Survey (USGS) (http://glovis.usgs.gov/). Data were acquired on 14 June 2000, and 25 September 2011. The path/row numbers were 134/031. 
The GIMMS NDVI dataset is a 15-day maximize NDVI value composite product with a spatial resolution of $8 \mathrm{~km}$. This dataset is derived from imagery obtained from the Advanced Very High Resolution Radiometer (AVHRR) instrument onboard the NOAA satellite series 7, 9, 11, 14, 16, and 17. To monitor vegetation growth conditions before the implementation of the EWDP in 2000, GIMMS NDVI data between 1990 and 2000 were used for this study, which were provided by the Environmental and Ecological Science Data Center for West China [33] (http://westdc.westgis.ac.cn). At the same time, in order to comprehensively monitor temporal and spatial changes in vegetation associated with land cover quality after the implementation of the EWDP, MODIS NDVI data products (MOD13Q1) between 2000 and 2011 were obtained from the Earth Resource Observation System (EROS) Center. MODIS NDVI data are based on 16-day composites. Its spatial resolution is $250 \mathrm{~m}$. GIMMS NDVI and MODIS NDVI data were acquired during the growing season, between April and October, to reflect vegetation growth and change.

In addition to remote sensing data sets, climate and hydrological data were also used in this study in order to analyze driving factors behind changes in land use and vegetation. Climate data were obtained from the Environmental and Ecological Science Data Center for West China [33] (http://westdc.westgis.ac.cn) while hydrological data were provided by the Heihe River Bureau. Data obtained from these resources included runoff, groundwater levels from 15 observation wells, and water volume flowing into Sogo Nuur and Gaxun Nuur between 2000 and 2011. Runoff was collected from two hydrological stations, Zhengyixia and Langxinshan stations, which separately recorded runoff at the outlet in the middle reaches and water flow that reached Ejin Oasis, respectively.

\subsection{Data Land Use Change Monitoring}

The land use map of the Ejin Oasis in 2000 (1:100,000 scale) was obtained from the National Land Use/Cover Database of China (NLUD-C), which was based on Landsat TM remotely sensed data and compiled by Liu [34,35] using the visual interpretation method. Based on land use data in 2000 and Landsat TM/ETM+ images in 2000 and 2011, a land use map in 2011 was also generated, using the visual interpretation method to guarantee classification consistency and accuracy. According to the NLUD-C land use classification system, the land use map of the Ejin Oasis was categorized into six primary types: farmland, forest land, grassland, water body, built-up land, and desert [34,35]. Based on the status of vegetation coverage, forest land was further divided into arboreal forest, shrub forest, and sparse forest. Similarly, grassland was further divided into thick grassland, moderate grassland, and sparse grassland. Water body in the study area included rivers, lakes, reservoirs, overflow land, and wetland.

Interpretation accuracy for the land use classification in 2000 was greater than $90 \%$ compared to results obtained from an intensive field survey $[35,36]$. In order to validate the land use map in 2011, two field investigations were conducted in May and November 2012, respectively. A total of 66 GPS points and approximately 269 photographs were obtained for this study. Overall accuracy for land use classification was $87.88 \%$. Farmland and water body accuracy was greater than $90 \%$.

Area data of various land use types between 2000 and 2011 were obtained using the statistics function provided by GIS. A transition matrix, which provided information related to the magnitude and direction of land use changes in the Ejin Oasis, was also generated using ArcGIS software. 


\subsection{SINDVI Change}

The Seasonally Integrated Normalized Difference Vegetation Index (SINDVI) is defined as the sum of NDVI values for each pixel and all time intervals related to maximum value composites (MVCs) for which NDVI exceeds a critical value (commonly NDVI >0.1) [36,37]. In this study, SINDVI was used as an indicator of annual vegetation growth in the study area.

In order to further estimate vegetation changes between 2000 and 2011, vegetation change trends were calculated using ordinary least squares (OLS) estimation by applying Equation (1) [36-38].

$$
\text { Slop }=\frac{12 \times \sum_{i=1}^{12} i \times \operatorname{SINDVI}_{i}-\left(\sum_{i=1}^{12} i\right)\left(\sum_{i=1}^{12} \operatorname{SINDVI}_{i}\right)}{12 \times \sum_{i=1}^{12} i^{2}-\left(\sum_{i=1}^{12} i\right)^{2}}
$$

where $i$ denotes 1 for year 2000, 2 for year 2001, etc.; SINDVI is the SINDVI value for year $i$; and Slop is the linear regression slope for the one variable equation. When Slop $>0$, this indicated that SINDVI increased throughout the 2000 and 2011 study period and vice versa.

\section{Results}

\subsection{Land Use Change Monitoring}

Changes in different land use types are a major indicator of general changes in an environment. Figure 2 and Table 1 show obvious LUCC that occurred in the Ejin Oasis between 2000 and 2011. The main LUCC characteristics were a significant increase in water body and farmland area and a decrease in grassland and desert area.

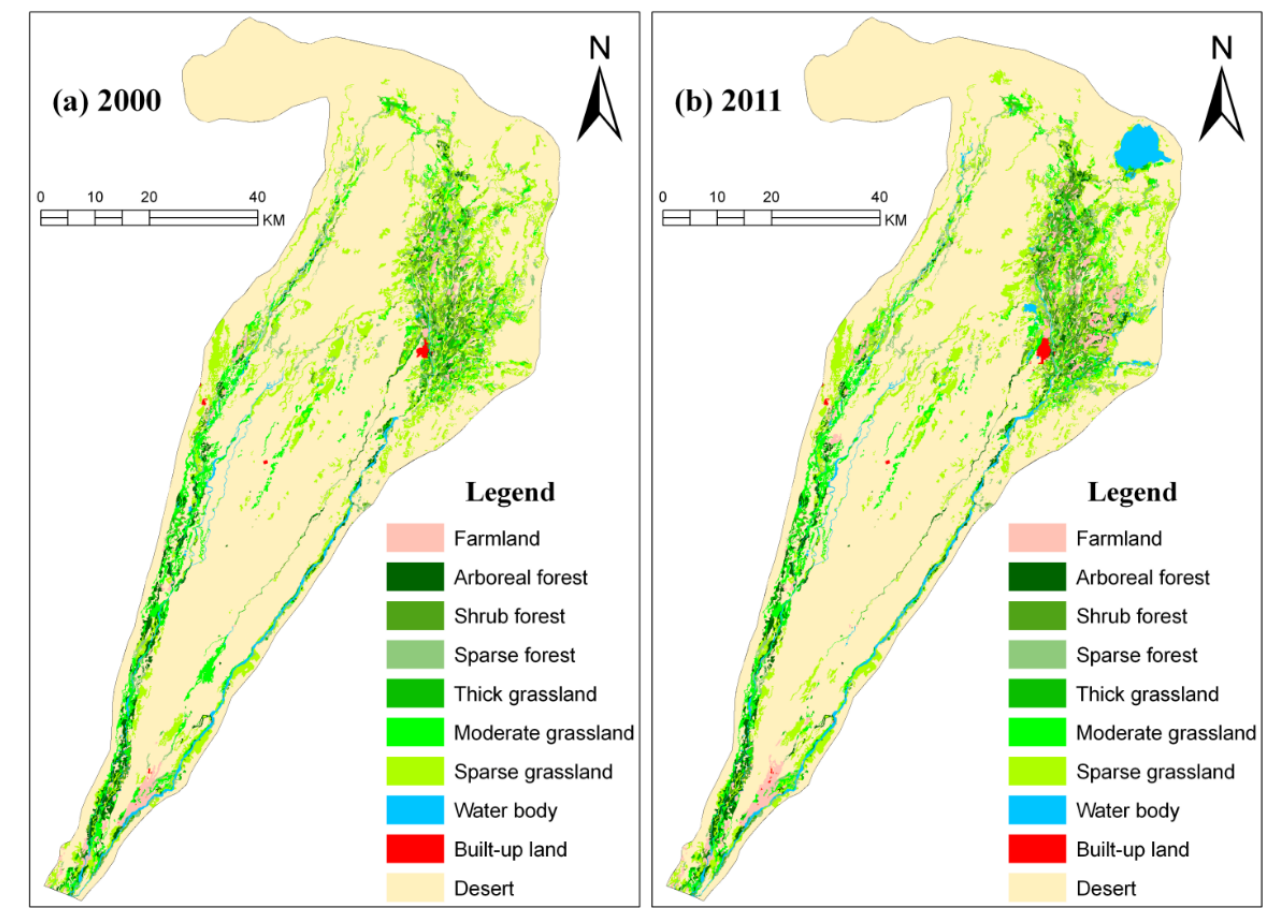

Figure 2. Land use maps of the study area in (a) 2000 and (b) 2011. 
Table 1. Changes in primary types of land use in the Ejin Oasis.

\begin{tabular}{cccccccc}
\hline \multirow{2}{*}{ Year } & Parameter & Farmland & $\begin{array}{c}\text { Forest } \\
\text { Land }\end{array}$ & Grassland & $\begin{array}{c}\text { Water } \\
\text { Body }\end{array}$ & $\begin{array}{c}\text { Built-up } \\
\text { Land }\end{array}$ & Desert \\
\hline \multirow{2}{*}{2000} & Area $\left(\mathrm{km}^{2}\right)$ & 71.50 & 379.03 & 927.69 & 70.04 & 6.92 & 4383.33 \\
& Percent $(\%)$ & 1.22 & 6.49 & 15.89 & 1.20 & 0.12 & 75.08 \\
\multirow{2}{*}{2011} & Area $\left(\mathrm{km}^{2}\right)$ & 130.32 & 401.08 & 905.23 & 144.17 & 10.97 & 4246.74 \\
& Percent (\%) & 2.23 & 6.87 & 15.50 & 2.47 & 0.19 & 72.74 \\
\multirow{2}{*}{$2000-2011$} & Area change $\left(\mathrm{km}^{2}\right)$ & 58.82 & 22.05 & -22.46 & 74.13 & 4.06 & -136.59 \\
& Percent $(\%)$ & 82.27 & 5.82 & -2.42 & 105.84 & 58.66 & -3.12 \\
\hline
\end{tabular}

Specifically, water body area increased from $70.04 \mathrm{~km}^{2}$ in 2000 to $144.17 \mathrm{~km}^{2}$ in 2011 , a $74.13 \mathrm{~km}^{2}$ overall increase. Changes in water body area were primarily caused by an increase in lake and wetland area. Among these changes, the lake area of Sogo Nuur increased to $45 \mathrm{~km}^{2}$, and the wetland area surrounding Sogo Nuur increased by $9 \mathrm{~km}^{2}$ (Figure 3).

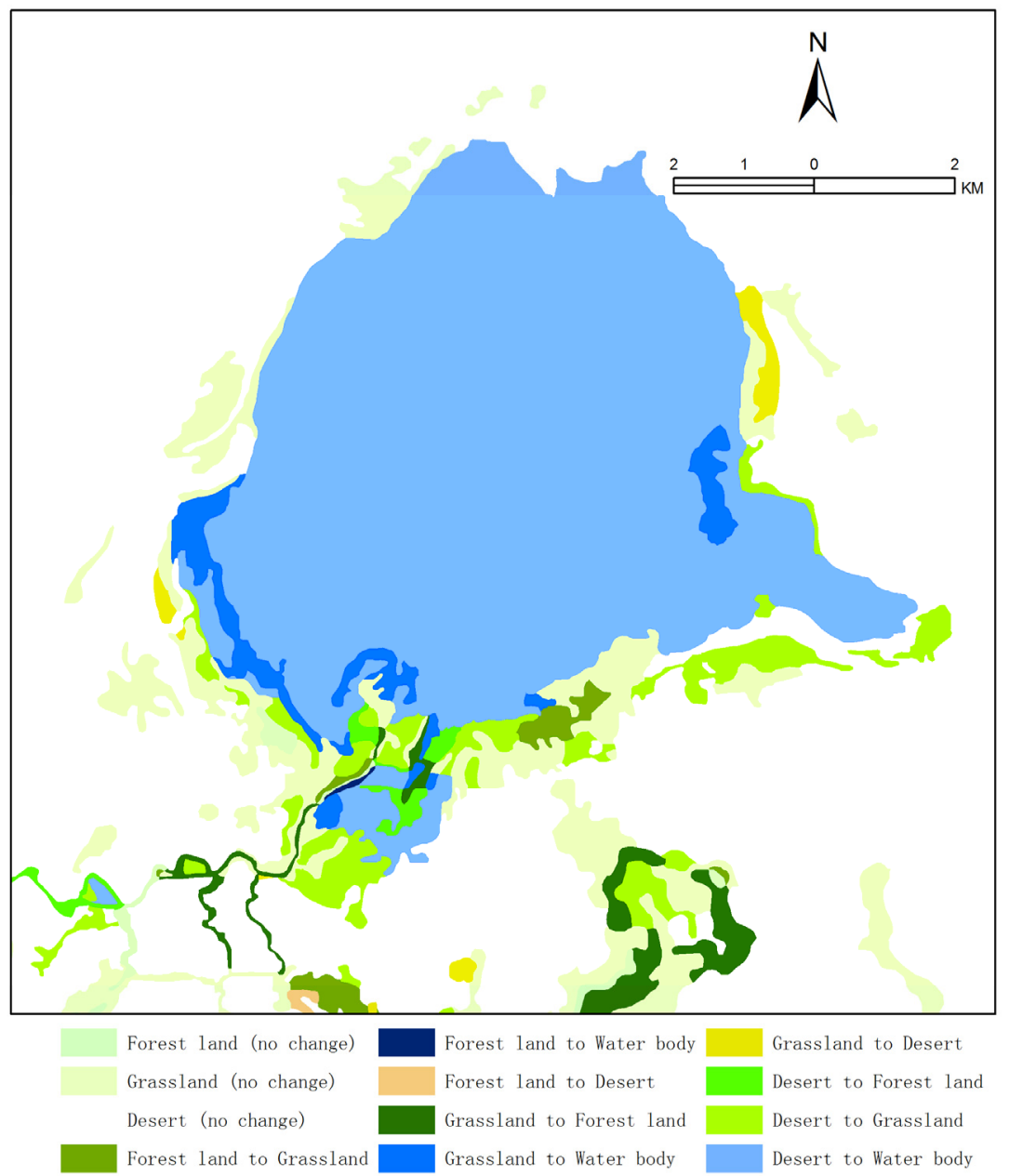

Figure 3. Land use changes around Sogo Nuur between 2000 and 2011.

Farmland is the land use type that experienced the second largest overall increase. Farmland area increased from $71.50 \mathrm{~km}^{2}$ in 2000 to $130.32 \mathrm{~km}^{2}$ in 2011 , a $58.82 \mathrm{~km}^{2}$ overall increase. The increase in farmland area was primarily caused by a decrease in grassland and desert area (Table 2). Approximately $35.09 \mathrm{~km}^{2}$ of grassland and $18.97 \mathrm{~km}^{2}$ of desert were converted to farmland, and this newly reclaimed 
farmland area was mainly situated in the middle region of the Ejin Oasis, which is located in the lower Donghe River region (Figure 4).

Table 2. Dynamic transition matrixes of land use types between 2000 and $2011\left(\mathrm{~km}^{2}\right)$.

\begin{tabular}{ccccccc}
\hline \multirow{2}{*}{2000} & \multicolumn{7}{c}{ 2011 } \\
\cline { 2 - 7 } & Farmland & Forest Land & Grassland & Water Body & Built-Up Land & Desert \\
\hline Farmland & 67.49 & 2.46 & 1.01 & 0.06 & 0.14 & 0.34 \\
Forest Land & 8.77 & 338.90 & 27.95 & 0.74 & 0.61 & 2.06 \\
Grassland & 35.09 & 54.15 & 787.29 & 8.97 & 0.39 & 41.80 \\
Water Body & 0.00 & 0.00 & 2.14 & 67.28 & 0.00 & 0.62 \\
Built-up Land & 0.00 & 0.00 & 0.12 & 0.01 & 6.72 & 0.07 \\
Desert & 18.97 & 5.57 & 86.72 & 67.11 & 3.11 & 4201.85 \\
\hline
\end{tabular}

Note: Rows represent land use type areas in 2000 and columns represent land use type areas in 2011. For example, the row 3 column 1 cell shows that $35.09 \mathrm{~km}^{2}$ was classified as grassland in 2000 and as farmland in 2011.

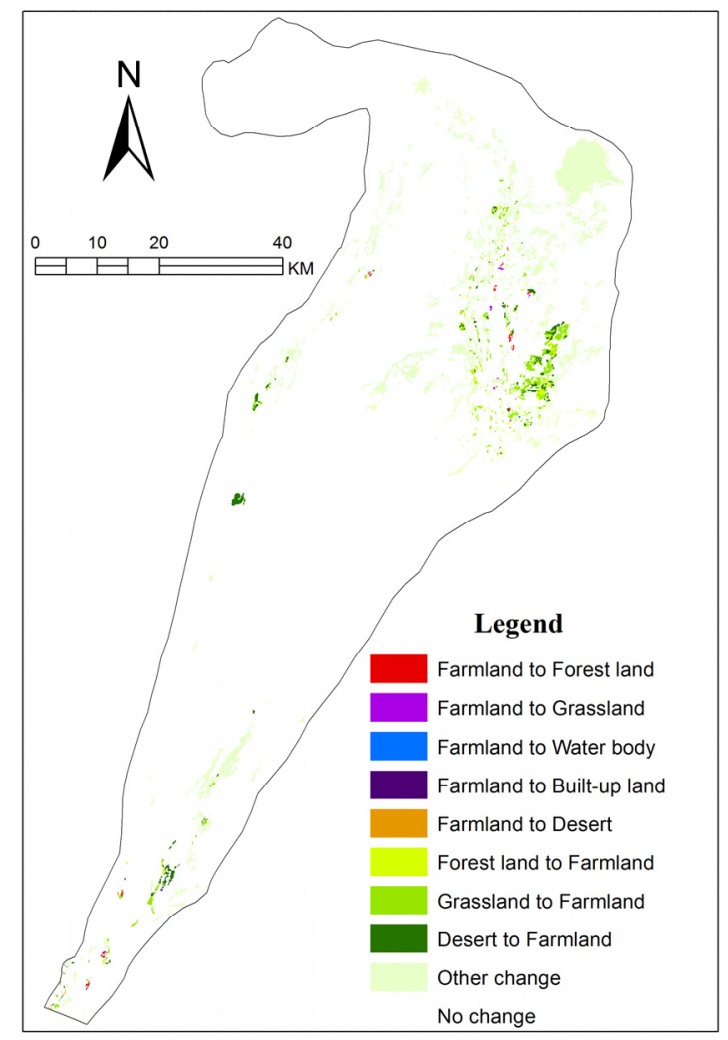

Figure 4. Changes in farmland area in the Ejin Oasis between 2000 and 2011.

Forest land area increased slightly, a $22.05 \mathrm{~km}^{2}$ overall increase. Increases in forest land area were primarily the result of its conversion from grassland. Total forest land area converted from grassland was $54.15 \mathrm{~km}^{2}$ between 2000 and 2011 (Table 2). The increase in forest land area primarily took place in the natural oasis of the lower Donghe River region.

In contrast to increases in area for the three aforementioned land use types, a decrease in grassland and desert area was observed during the study period (2000-2011). Grassland area decreased from $927.69 \mathrm{~km}^{2}$ in 2000 to $905.23 \mathrm{~km}^{2}$ in 2011 , a $22.46 \mathrm{~km}^{2}$ overall decrease. The reduction in grassland area was the result of two factors. First, a large expanse of grassland was reclaimed into farmland 
(a total of $35.09 \mathrm{~km}^{2}$ of grassland was converted into farmland). Second, the implementation of the EWDP led to changes in spatial distribution of water resources, resulting in a conversion from grassland to shrub forest and sparse forest, and from sparse grassland to desert (approximately $54.15 \mathrm{~km}^{2}$ and $41.80 \mathrm{~km}^{2}$ of grassland was converted into forest land and desert, respectively) (Table 2). Total desert area decreased by $136.59 \mathrm{~km}^{2}$ between 2000 and 2011 .

\subsection{SINDVI Change}

Significant differences were observed in the spatial distribution of vegetation cover in the Ejin Oasis (Figure 5). Vegetation cover in the upper and lower regions of the Donghe River was greater than in the middle region. Alongside the Xihe River, moreover, vegetation cover in the upper and middle regions was greater than in the lower reaches.

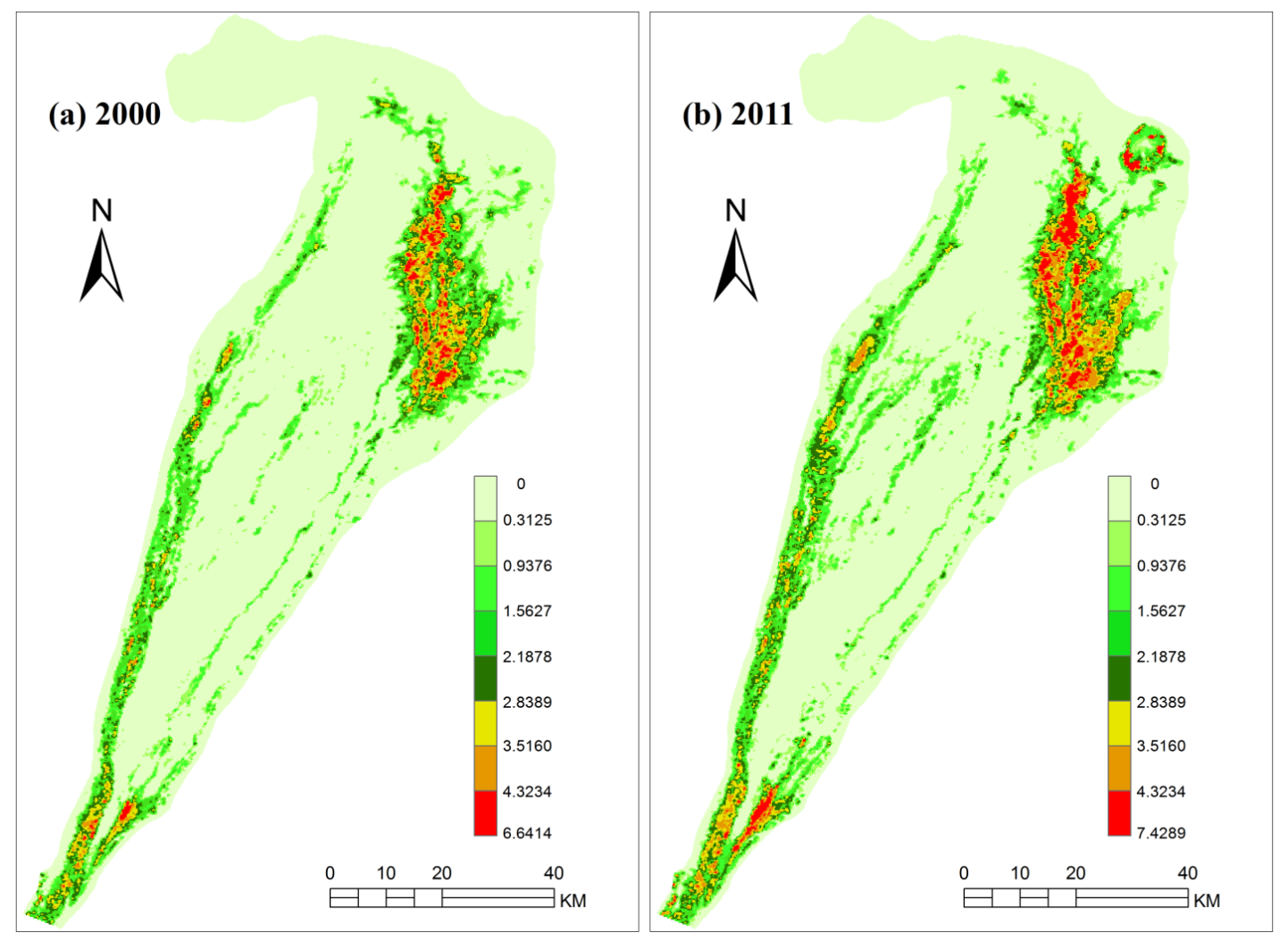

Figure 5. SINDVI maps in 2000 and 2011.

Long-term SINDVI trend analysis showed that SINDVI exhibited a decreasing trend, and there was a decline in vegetation growth between 1990 and 2000 (Figure 6). However, after the implementation of the EWDP in 2000, a general increase in SINDVI took place in the Ejin Oasis, and vegetation cover gradually began to recover (Figures 6, 7 and Table 3). Between 2000 and 2011, areas showing an increase in SINDVI totaled $31.18 \%$ of the entire study area, primarily consisting of areas showing only slight increases $(22.48 \%$ ). Areas showing moderate increases totaled $8.21 \%$, primarily in the middle Xihe River region and the upper and lower Donghe River regions. Areas showing high increases totaled $0.49 \%$ of the study area, primarily around Sogo Nuur and in the middle Xihe River region. On the other hand, certain regions showed a decrease in SINDVI. Such regions totaled $4.58 \%$ of the Ejin Oasis. Areas showing high decreases totaled $0.26 \%$. Decreases in SINDVI occurred around the intersection of the 
Donghe and Xihe rivers, the lower Xihe River region, both sides of Nalin River in the middle Donghe River region, and the border area of the artificial canal in the lower Donghe River region of the Ejin Oasis. Such trends indicated that two coexisting yet opposite processes existed concurrently in landscape evolution in the region, namely, Ejin Oasis expansion and desertification (for which expansion was the dominant process). Regions that remained relatively stable totaled $64.24 \%$ of the study area. These regions were located between the Donghe and Xihe rivers and around Gaxun Nuur in the lower Xihe River region, and were primarily of the desert land type.

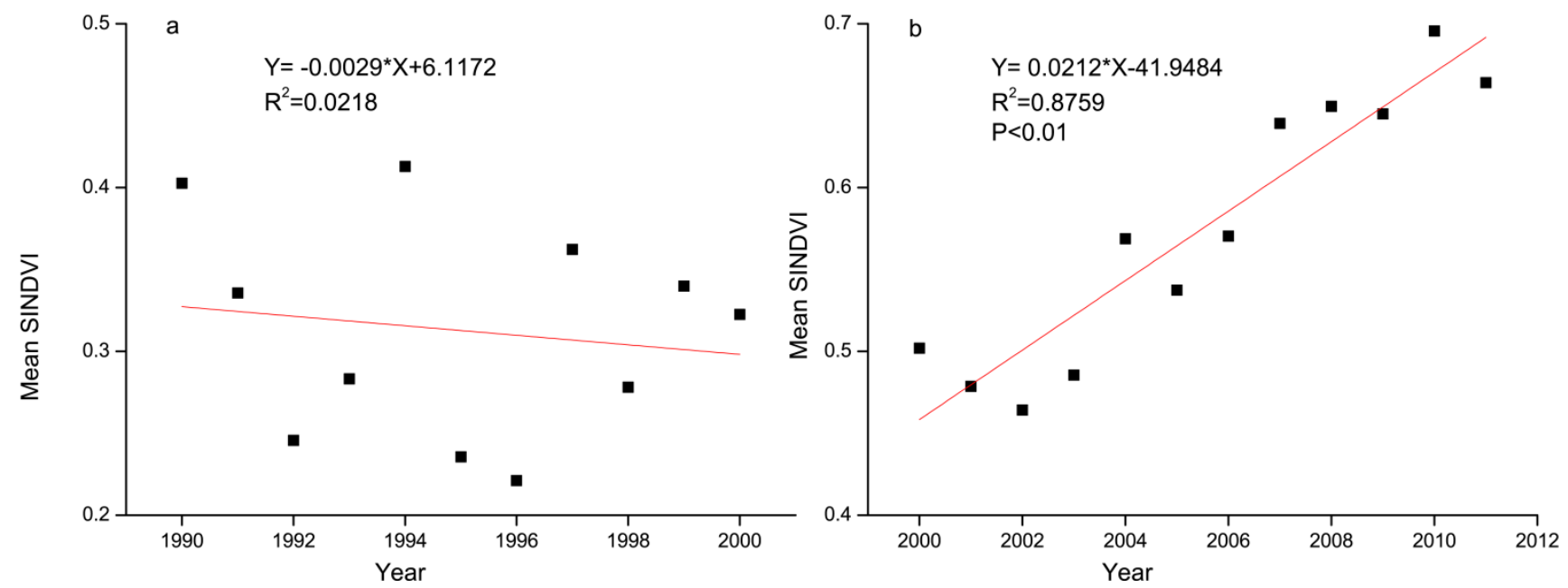

Figure 6. Long-term SINDVI changes in the Ejin Oasis between 1990 and 2011: (a) SINDVI changes between 1990 and 2000 were based on GIMMS NDVI data, and (b) SINDVI changes between 2000 and 2011 were based on MODIS NDVI data.

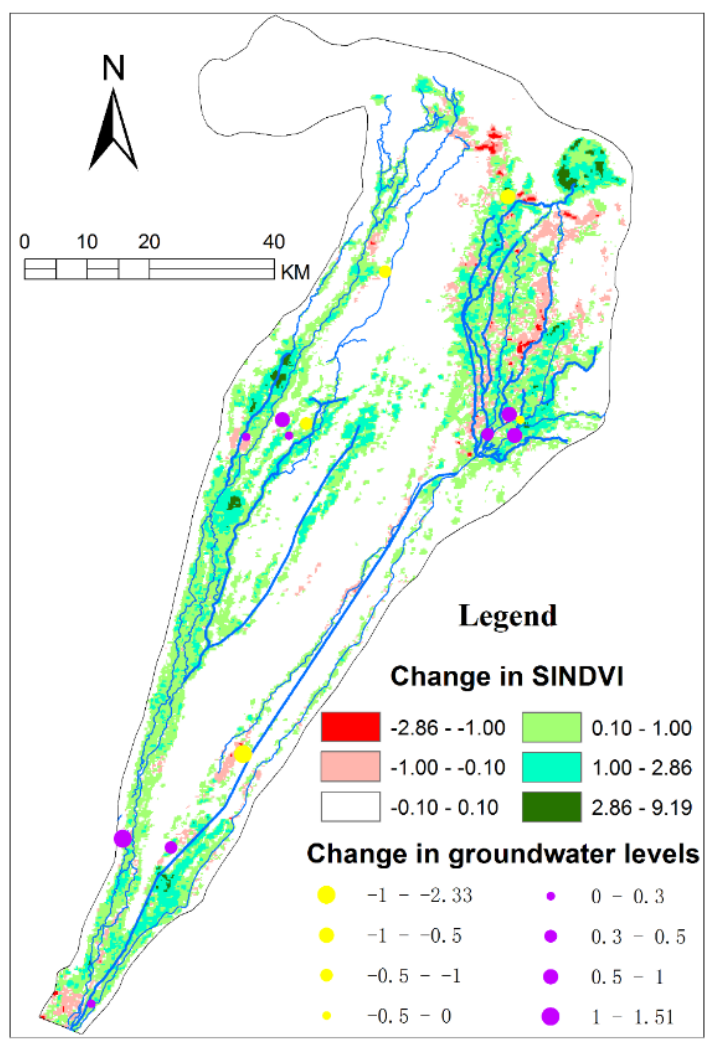

Figure 7. Changes in SINDVI and groundwater levels in the Ejin Oasis between 2000 and 2011. 
Table 3. Area statistics of seasonally integrated normalized difference vegetation index (SINDVI) changes in the Ejin Oasis between 2000 and 2011.

\begin{tabular}{ccc}
\hline Degree of SINDVI Changes & Range of SINDVI Changes & Area (\%) \\
\hline High range decreases & $-2.86 \sim-1.00$ & 0.26 \\
Lower range decreases & $-1.00 \sim-0.10$ & 4.32 \\
Relatively stable & $-0.10 \sim+0.10$ & 64.24 \\
Lower range increases & $+0.10 \sim+1.00$ & 22.48 \\
Medium range increases & $+1.00 \sim+2.86$ & 8.21 \\
Higher range increases & $+2.86 \sim+9.19$ & 0.49 \\
\hline
\end{tabular}

\section{Discussion}

\subsection{Driving Factors behind Ecosystem Recovery}

Water resources had a significant impact on ecosystems situated in the extremely arid lower reaches. Figure 8 shows that no significant decreases in annual precipitation occurred in the Ejin Oasis between 1960 and 2011. However, mean annual precipitation was greater between 1960 and 2011 compared to the 1980s and between 2000 and 2011. A significant decrease in annual precipitation was also observed between the 1990s and 2011. Annual temperature continuously increased between 2000 and 2011. This was not consistent throughout the warm-wet climate of the HRB as a whole because the Ejin Oasis is surrounded by desert and belongs to the extreme arid climate zone. Under such climatic conditions, increases in water consumption caused by increases in temperature may offset annual precipitation. Thus, annual precipitation would not play a key role in vegetation recovery and lake restoration. Moreover, no significant correlations between changes in SINDVI and annual precipitation were observed (the correlation coefficient between SINDVI values based on GIMMS NDVI and annual precipitation was 0.270 , and the correlation coefficient between SINDVI values based on MODIS NDVI and annual precipitation was 0.129 ). The overall Ejin Oasis ecosystem was therefore primarily dependent on water resources flowing into the Ejin Oasis from the middle reaches.
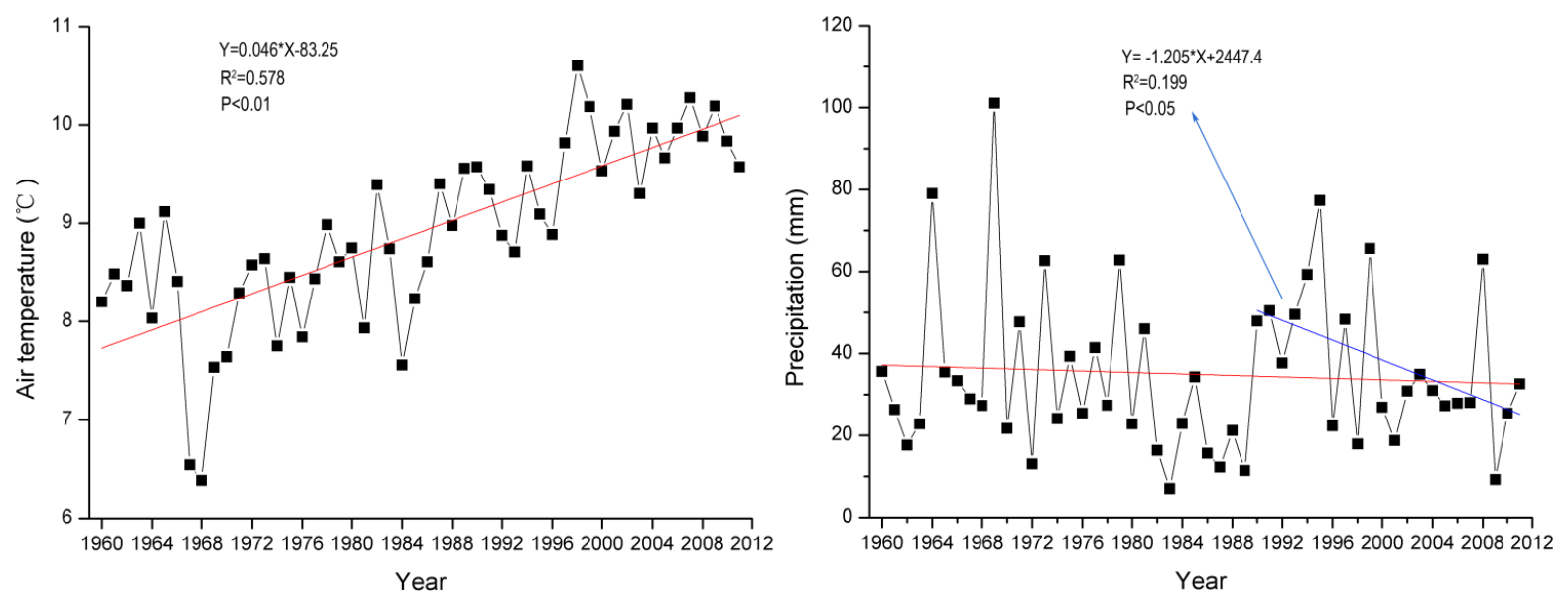

Figure 8. Trends in annual temperature and annual precipitation in the Ejin Oasis between 1960 and 2011. The red line denotes trends in temperature and precipitation changes between 1960 and 2011, respectively. The blue line denotes trends in precipitation changes between 1990 and 2011. 
Runoff from the Zhengyixia hydrological station, which recorded water flow entering the lower reaches from the middle reaches, decreased significantly between the 1960s and 1990s due to large-scale expansion of irrigated farmland in the middle reaches. Multi-year average runoff from the Zhengyixia hydrological station decreased by $2.84 \times 10^{8} \mathrm{~m}^{3}$ between the 1960s and 1990s [39]. Similarly, runoff from the Langxinshan hydrological station located downstream of the Zhengyixia hydrological station, which recorded water flow into the Ejin Oasis, also showed a significant decreasing trend. Furthermore, the decrease in the amount of runoff from the Langxinshan hydrological station was greater compared to the Zhengyixia hydrological station due to an increase in water diversion from Dongfeng irrigation districts, which are situated between Zhengyixia and Langxinshan stations. During the 1990s, multi-year average runoff from the Langxinshan hydrological station was $3.47 \times 10^{8} \mathrm{~m}^{3}$, a decrease of $3.93 \times 10^{8} \mathrm{~m}^{3}$ compared to 1960-1969 [40]. The decrease in water entering into the Ejin Oasis led to its ecosystem deterioration. The lake area of Gaxun Nuur and Sogo Nuur were $267 \mathrm{~km}^{2}$ and $35.5 \mathrm{~km}^{2}$ in 1958 , respectively, and dried-up in 1961 and 1992, respectively [24,41]. Vegetation growth receded and SINDVI values based on GIMMS NDVI data decreased in the 1990s (Figure 6). However, with the successful implementation of the EWDP, a total water volume of $120.03 \times 10^{8} \mathrm{~m}^{3}$ from the Zhengyixia hydrological station was released into the lower reaches of the HRB between 2000 and 2011, which is greater by a factor of $42.49 \times 10^{8} \mathrm{~m}^{3}$ compared to the $1990 \mathrm{~s}$. At the Langxinshan hydrological station, a total water volume of $55.96 \times 10^{8} \mathrm{~m}^{3}$ was allowed to flow into the Ejin Oasis between 2000 and 2011, an amount greater by a factor of $18.38 \times 10^{8} \mathrm{~m}^{3}$ compared to the $1990 \mathrm{~s}$ (Figure 9). The first instance of water reaching Sogo Nuur occurred in 2002 after it had been dried-up for approximately 10 years, and lake area has remained at a level greater than $40 \mathrm{~km}^{2}$ since 2008 . Total water volume reaching Sogo Nuur was $5.66 \times 10^{8} \mathrm{~m}^{3}$ between 2000 and 2011. The first instance of water reaching Gaxun Nuur occurred in 2003, and total water volume reaching this lake was $0.29 \times 10^{8} \mathrm{~m}^{3}$ between 2000 and 2011 . Increased amounts of water allowed to flow into the lower reaches led to the restoration of the lakes and supported vegetation recovery in the Ejin Oasis.

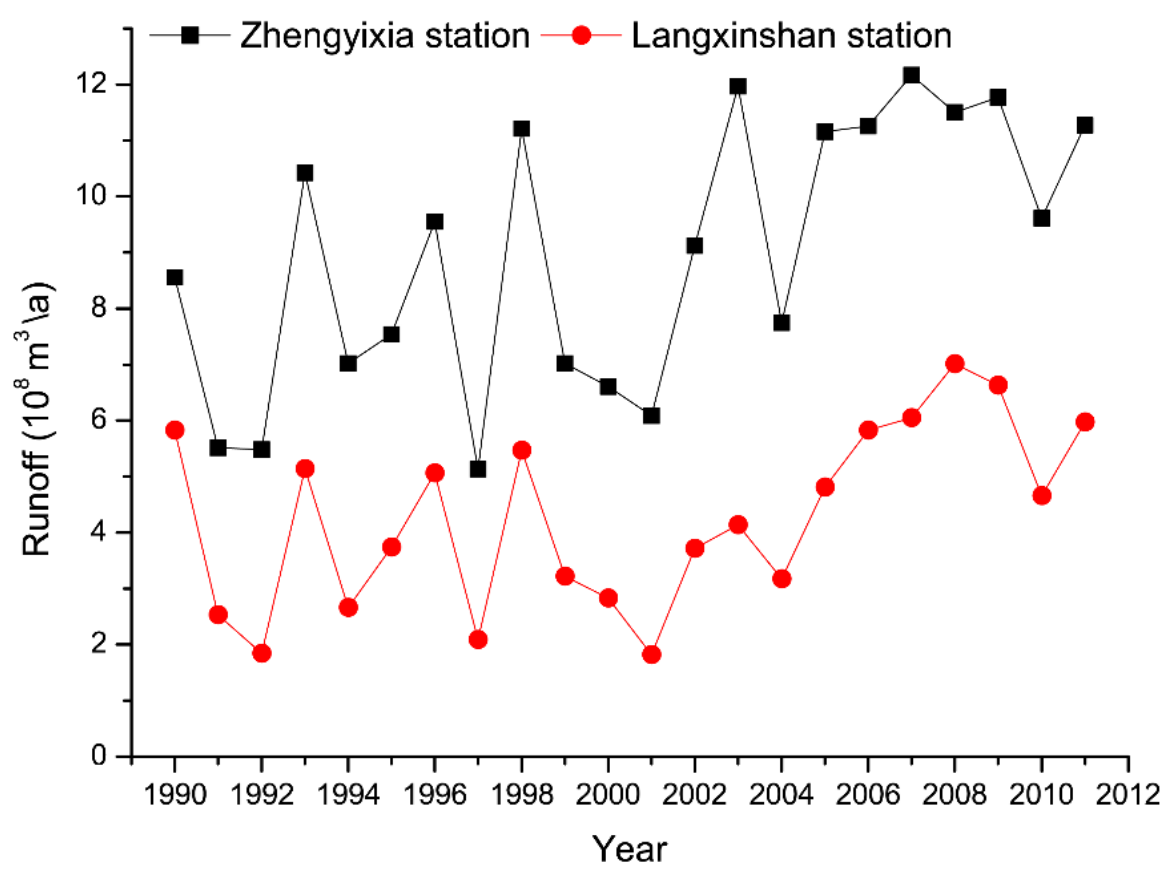

Figure 9. Runoff from the Zhengyixia and Langxinshan hydrological stations between 1990 and 2011. 
In order to further evaluate the impact of the EWDP on vegetation cover changes, SINDVI values based on MODIS NDVI data between 2000 and 2011 were analyzed against runoff from previous years at the Langxinshan hydrological station. As shown in Table 4, correlation coefficients reached their maximum values when lag time was one year, indicating a good correlation between SINDVI and previous year runoff at the Langxinshan hydrological station. Similarly, SINDVI values based on GIMMS NDVI data between 1990 and 2000 and runoff from the previous year at the Langxinshan hydrological station were correlated (the correlation coefficient value was 0.692). Other studies reported similar results $[40,42,43]$. The lag time effect of runoff on vegetation growth implied that vegetation growth in the Ejin Oasis depends on groundwater because conversion between surface water and groundwater takes a certain amount of time.

Table 4. Correlation coefficients between SINDVI values and runoff at the Langxinshan hydrological station.

\begin{tabular}{cccccc}
\hline Correlation & Same & \multicolumn{4}{c}{ Previous Years } \\
\cline { 3 - 6 } Coefficients & Year & One Year & Two Years & Three Years & Four Years \\
\hline $\mathbf{r}$ & 0.729 & 0.903 & 0.837 & 0.600 & 0.385 \\
\hline
\end{tabular}

Figure 10 shows groundwater levels that declined as a result of a decrease in incoming water from the Langxinshan hydrological station in the 1990s. However, after the implementation of the EWDP, groundwater levels exhibited a general upward trend between 2000 and 2010 (Figure 10). Moreover, as shown in Figure 7, groundwater levels rose in the upstream and midstream regions of the Donghe and Xihe rivers between 2000 and 2011, the same regions for which increasing SINDVI values were observed. On the other hand, groundwater levels declined in a number of downstream regions as well as the edge of the Ejin Oasis itself, the same regions for which decreasing SINDVI values were observed.

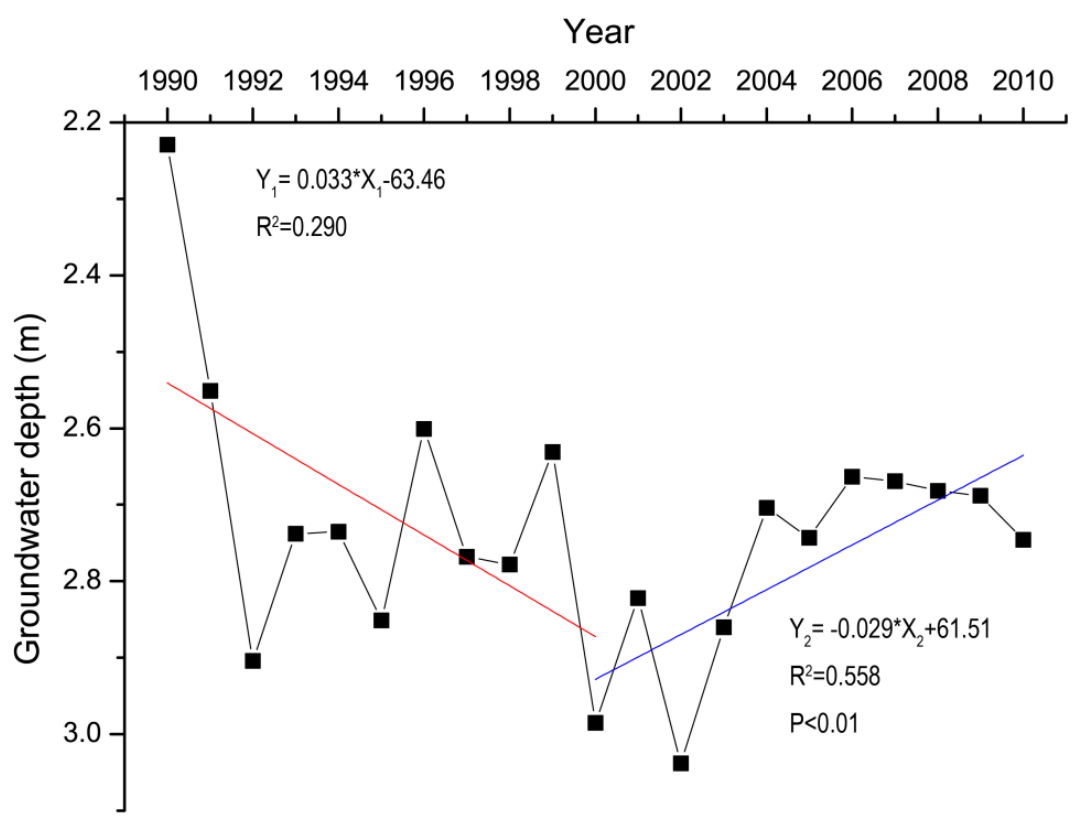

Figure 10. Average groundwater level changes in the Ejin Oasis between 1990 and 2010. The red and blue lines denote trends in groundwater level changes between 1990 and 2000 and between 2000 and 2010, respectively. 
Additionally, the implementation of supplementary ecological protection projects, which included the development of forage bases as well as the building of "living" fences and natural vegetation irrigation systems, was also beneficial to the ecosystem recovery in the Ejin Oasis.

\subsection{Reasons behind Farmland Expansion}

Farmland expansion occurred rapidly in the Ejin Oasis after the implementation of the EWDP in 2000. Throughout the entire 2000-2011 study period, for example, the percentage increase in farmland area was $82.27 \%$ (Table 1). Like other arid regions in northwestern China (e.g., Xinjiang and the Qaidam Basin in Qinghai Province), socioeconomic development affected the evolution of land use patterns. After 2000, socioeconomic development proceeded rapidly in the Ejin Oasis. In 2011, GDP was 39.89 billion CNY, an increase by a factor of 27.69 compared to GDP in 2000 [44]. The average annual growth rate in GDP between 2000 and 2011 was approximately 31.89\%. Moreover, the average annual growth rate of primary, secondary, and tertiary industry was $10.40 \%, 39.79 \%$, and $30.38 \%$, respectively. To increase income, local people expanded farmland area to grow crops yielding high economic benefits, such as melons. In 2000, melon planting area accounted for $9.42 \%$ of total crop area, and this percentage reached $68.62 \%$ in 2011 [44]. Income from growing melons is greater than 13,000 CNY/ha, which is the main economic source behind the increase in farmer's incomes [45]. It is obvious that the strong pursuit of economic benefits was a significant factor behind the increase in farmland area in the Ejin Oasis. Additionally, increases in water flow in the lower reaches also provided conditions for farmland reclamation or the reclamation of abandoned farmland.

\subsection{Reasons behind Ecosystem Degradation in Particular Areas}

Land use and SINDVI analyses have also shown ecosystem deterioration in particular areas of the Ejin Oasis even though the overall ecosystem has generally improved between 2000 and 2011. Apart from factors related to water scarcity, ecosystem deterioration resulting from a substantial increase in farmland area must be taken into account. First, farmland in the Ejin Oasis primarily depends upon groundwater extraction. A substantial increase in farmland area will inevitably lead to the overexploitation of groundwater and result in the transfer (loss) of water from ecosystems. Second, a substantial expansion in farmland area also accompanies a decrease in grassland area. Between 2000 and 2011, for example, approximately $35.09 \mathrm{~km}^{2}$ of grassland was converted into farmland. Such measures hinder the ecological restoration of the Ejin Oasis.

Additionally, the deterioration of vegetation in particular areas was to some extent also a product of the adopted water resource management approach taken. For example, vegetation degradation in the lower Xihe River region was a result of the inadequate volume of water released into Xihe River. At the same time, almost no water has reached Gaxun Nuur in the past 12 years with the exception of 2003 and 2008 when a limited volume of water flowed into the lake. In the lower Donghe River region, however, many canals have been lined as part of the implementation of the EWDP, and this has prevented the overflow and infiltration of surface water, hindering the restoration of surface water and groundwater. Vegetation degradation therefore takes place alongside artificial canals (Figure 7). 


\section{Conclusions}

Land use has changed significantly in the Ejin Oasis between 2000 and 2011. The main characteristics of this change have been a dramatic increase in water body and farmland area. Water body area increased significantly. The lake area of the once dried-up Sogo Nuur increased to $45 \mathrm{~km}^{2}$. Farmland area almost doubled between 2000 and 2011. Forest land area, on the other hand, increased only slightly. Vegetation cover has also undergone significant recovery. Areas showing SINDVI increases totaled $31.18 \%$ for the entire study area. Increases in SINDVI primarily took place in the middle Xihe River regions, the upper and lower Donghe River regions, and the surrounding Sogo Nuur area. In summary, the entire Ejin Oasis ecosystem has generally improved between 2000 and 2011 even though ecosystem deterioration continues in particular areas.

Vegetation recovery and lake restoration were the result of the implementation of the EWDP, which significantly increased rates of water flowing into the lower reaches. Farmland expansion was due to a strong pursuit of economic benefit by local farmers. However, strict control of farmland and the implementation of the Grain for Green program are not only national policies but are also the cornerstone of harmonious utilization of water resources for the entire basin region. If farmland area cannot be controlled within a certain range, the EWDP will likely fail, and the comprehensive restoration of the overall ecosystem will unlikely be attained. Therefore, it is strongly recommended that unreasonable and unsustainable applications of land use should be controlled in the Ejin Oasis so that more water can be used for ecological restoration.

Results from this study suggest that the rational allocation of water resources in this arid inland basin and coordinated eco-economical development is effectively achievable. Furthermore, these results could provide a reference for the management of other inland river basins.

\section{Acknowledgments}

This study was jointly supported by the CAS (Chinese Academy of Sciences) Action Plan for West Development project (grant No. KZCX2-XB3-15) and the NSFC (National Natural Science Foundation of China) project (Grant NO. 41101388, 91125001 and 09XSH014).

\section{Author Contributions}

Xiaoli $\mathrm{Hu}$, Ling $\mathrm{Lu}$, and Xin Li designed the research strategy. Xiaoli Hu, Jianhua Wang, and Xuegang Lu conducted the research and analyzed data with guidance from Ling Lu and Xin Li. Xiaoli Hu wrote the manuscript. Lastly, Xin Li provided valuable suggestions for the revision of this paper.

\section{Conflicts of Interest}

The authors declare no conflict of interest.

\section{References}

1. Prinz, D.; Singh, A.K. Water resources in Arid Regions and their sustainable management. Ann. Arid Lands 2000, 39, 251-272. 
2. Pereira, L.S.; Oweis, T.; Zairi, A. Irrigation management under water scarcity. Agric. Water Manag. 2002, 57, 175-206.

3. Chen, Y.N.; Cui, W.C.; Li, W.H.; Chen, Y.P.; Zhang, H.F. Utilization of water resources and ecological protection in the Tarim River. Acta Geogr. Sin. 2003, 58, 215-222.

4. Paulo, A.A.; Pereira, L.S. Drought concepts and characterization: Comparing drought indices applied at local and regional scales. Water Int. 2006, 31, 37-49.

5. Micklin, P. The Aral Sea disaster. Ann. Rev. Earth Planet. Sci. 2007, 35, 47-72.

6. Chen, Y.; Chen, Y.P.; Xu, C.C.; Ye, Z.X.; Li, Z.Q.; Zhu, C.G.; Ma, X.D. Effects of ecological water conveyance on groundwater dynamics and riparian vegetation in the lower reaches of Tarim River, China. Hydrol. Process. 2010, 24, 170-177.

7. Turner, B.L.; Lambin, E.F.; Reenberg, A. The emergence of land change science for global environmental change and sustainability. Proc. Natl. Acad. Sci. USA 2007, 104, 20666-20671.

8. Luo, G.P.; Zhou, C.H.; Chen, X.; Li, Y. A methodology of characterizing status and trend of land changes in oases: A case study of Sangong River watershed, Xinjiang, China. J. Environ. Manag. 2008, 88, 775-783.

9. Lambin, E.F. Change detection at multiple temporal scales: Seasonal and annual variations in landscape variables. Photogramm. Eng. Remote Sens. 1996, 62, 931-938.

10. Brannstrom, C.; Jepson, W.; Filippi, A.M.; Redo, D.; Xu, Z.W.; Ganesh, S. Land change in the Brazilian Savanna (Cerrado), 1986-2002: Comparative analysis and implications for land-use policy. Land Use Policy 2008, 25, 579-595.

11. Ruelland, D.; Tribotte, A.; Puech, C.; Dieulin, C. Comparison of methods for LUCC monitoring over 50 years from aerial photographs and satellite images in a Sahelian catchment. Int. J. Remote Sens. 2011, 32, 1747-1777.

12. Sleeter, B.M.; Sohl, T.L.; Loveland, T.R.; Auch, R.F.; Acevedo, W.; Drummond, M.A.; Sayler, K.L.; Stehman, S.V. Land-cover change in the conterminous United States from 1973 to 2000. Glob. Environ. Chang. 2013, 23, 733-748.

13. Wondie, M.; Schneider, W.; Melesse, A.M.; Teketay, D. Spatial and temporal land cover changes in the Simen Mountains National Park, a world heritage site in Northwestern Ethiopia. Remote Sens. 2011, 3, 752-766.

14. Giri, C.; Long, J. Land cover characterization and mapping of South America for the year 2010 using Landsat $30 \mathrm{~m}$ satellite data. Remote Sens. 2014, 6, 9494-9510.

15. Curatola Fernandez, G.F.; Obermeier, W.A.; Gerique, A.; Sandoval, M.; Lehnert, L.W.; Thies, B.; Bendix, J. Land cover change in the Andes of Southern Ecuador - Patterns and drivers. Remote Sens. 2015, 7, 2509-2542.

16. Foley, J.A.; Defries, R.; Asner, G.P.; Barford, C.; Bonan, G.; Carpenter, S.R.; Stuart Chapin, F.; Coe, M.T.; Daily, G.C.; Gibbs, H.K.; et al. Global consequences of land use. Science 2005, 309, 570-574.

17. Liu, Y.S.; Chen, B.M. The study framework of land use/cover change based on sustainable development in China. Geogr. Res. 2002, 21, 324-330.

18. Xiao, S.C.; Xiao, H.L. The Impact of Human Activity on the Water Environment of HeiHe Water basin in Last Century. J. Arid Land Resour. Environ. 2004, 3, 57-62. 
19. Wang, J.; Meng, J.J. Characteristics and tendencies of annual runoff variations in the Heihe River Basin during the past 60 years. Sci. Geogr. Sin. 2008, 28, 83-88.

20. Lu, L.; Li, X.; Cheng, G.D. Landscape evolution in the middle Heihe River Basin of northwest China during the last decade. J. Arid Environ. 2003, 53, 395-408.

21. Qin, C.; Yang, B.; Burchardt, I.; Hu, X.L.; Kang, X.C. Intensified pluvial conditions during the twentieth century in the inland Heihe River Basin in arid northwestern China over the past millennium. Glob. Planet. Chang. 2010, 72, 192-200.

22. Yang, B.; Qin, C.; Shi, F.; Sonechkin, D.M. Tree ring-based annual streamflow reconstruction for the Heihe River in arid northwestern China from AD 575 and its implications for water resource management. Holocene 2011, 22, 773-784.

23. Shi, Y.F.; Shen, Y.P.; Li, D.L.; Zhang, G.W; Ding, Y.J.; Hu, R.J.; Kang, E.S. Discussion on the present climate change from warm-dry to warm-wet in northwest China. Quat. Sci. 2003, 23, $152-164$.

24. Liu, Y.C. Evolution of the Juyan lake. J. Arid Land Resour. Environ. 1992, 6, 9-18.

25. Cheng, G.D. Saving water is the only way for Northwest China to survive. Bull. Chin. Acad. Sci. 1996, 10, 203-206.

26. Wang, G.; Cheng, G. Water resource development and its influence on the environment in arid areas of China-The case of the Hei River basin. J. Arid Environ. 1999, 43, 121-131.

27. Li, X.; Lu, L.; Cheng, G.; Xiao, H. Quantifying landscape structure of the Heihe River Basin, north-west China using FRAGSTATS. J. Arid Environ. 2001, 48, 521-535.

28. Cheng, G.D.; Wang, G.X. Changing trend of drought and drought disaster in northwest China and countermeasures. Earth Sci. Front. 2006, 13, 3-14.

29. Lu, L.; Li, X.; Veroustraete, F.; Kang, E.S.; Wang, J.H. Analysing the forcing mechanisms for net primary productivity changes in the Heihe River Basin, north-west China. Int. J. Remote Sens. 2009, 30, 793-816.

30. Liu, H.; Cai, X.M.; Geng, L.H.; Zhong, H.P. Restoration of pastureland ecosystems: Case study of Western Inner Mongolia. J. Water Resour. Plan. Manag. 2005, 131, 420-430.

31. Cheng, G.D.; Li, X.; Zhao W.Z.; Xu Z.M.; Feng Q.; Xiao S.C.; Xiao, H.L. Integrated study of the water-ecosystem-economy in the Heihe River Basin. Natl. Sci. Rev. 2014, 1, 413-428.

32. Feng, Q.; Cheng, G.D.; Endo, K.N. Towards sustainable development of the environmentally degraded River Heihe basin, China. Hydrol. Sci. J. 2001, 46, 647-658.

33. Li, X.; Nan, Z.T.; Cheng, G.D.; Ding, Y.J.; Wu, L.Z.; Wang, L.X.; Wang, J.; Ran, Y.H.; Li, H.X.; Pan, X.D.; et al. Toward an improved data stewardship and service for environmental and ecological science data in west China. Int. J. Digit. Earth 2011, 4, 347-359.

34. Liu, J.Y.; Liu, M.L.; Zhuang, D.F.; Zhang, Z.X.; Deng, X.Z. Study on spatial pattern of land-use change in China during 1995-2000. Sci. China Ser. D 2003, 46, 373-384.

35. Liu, J.Y.; Liu, M.L.; Tian, H.Q.; Zhuang, D.F.; Zhang, Z.X.; Zhang, W.; Tang, X.M.; Deng, X.Z. Spatial and temporal patterns of China's cropland during 1990-2000: An analysis based on Landsat TM data. Remote Sens. Environ. 2005, 98, 442-456.

36. Stow, D.; Daeschner, S.; Hope, A.; Douglas, D.; Petersen, A.; Myneni, R.; Zhou, L.; Oechel, W. Variability of the Seasonally Integrated Normalized Difference Vegetation Index Across the North Slope of Alaska in the 1990s. Int. J. Remote Sens. 2003, 24, 1111-1117. 
37. Ma, M.G.; Frank, V. Interannual variability of vegetation cover in the Chinese Heihe River Basin and its relation to meteorological parameters. Int. J. Remote Sens. 2006, 27, 3473-3486.

38. Song, Y.; Ma, M.G. Variation of AVHRR NDVI and its relationship with climate in Chinese arid and cold regions. J. Remote Sens. 2008, 12, 499-505.

39. Ding, H.W.; Gao, Y.Z.; He, J.H.; Cao, B.Y. Reason of runoff reducing through Zhangyixia Gorge on Heihe River and Countermeasures. J. Desert Res. 2001, 21, 62-65.

40. Jin, X.M.; Schaepman, M.; Clevers, J.; Su, Z.B.; Hu, G.C. Correlation between annual runoff in the Heihe River to the vegetation cover in the Ejina Oasis (China). Arid Land Res. Manag. 2010, 24, $31-41$.

41. Gao, Q.Z.; Li, F.X. Rational Development and Utilization Of Water Resources in Heihe River Basin; Gansu Science and Technology Press: Lanzhou, China, 1990; pp. 91-92.

42. Jia, L.; Shang, H.; Hu, G.; Menenti, M. Phenological response of vegetation to upstream river flow in the Heihe River basin by time series analysis of MODIS data. Hydrol. Earth Syst. Sci. 2011, 15, $1047-1064$.

43. Jin, X.M.; Hu, G.C.; Li, W.M. Hysteresis effect of runoff of the Heihe River on vegetation cover in Ejin Oasis in Northwestern China. Earth Sci. Front. 2008, 15, 198-203.

44. Ejina Banner Bureau of statistics. Main economic indicators of Ejina Banner during 2000-2011. Available online: http://www.ejnqtj.gov.cn/Class.asp?ID=38\&page=1 (accessed on 29 January 2015).

45. Zhou, L.H.; Yang, G.J. Screening and evaluation of agricultural specialty industries in Ejina Banner located in the lower reaches of the Heihe River. Agric. Res. Arid Areas 2005, 23, 192-196.

(C) 2015 by the authors; licensee MDPI, Basel, Switzerland. This article is an open access article distributed under the terms and conditions of the Creative Commons Attribution license (http://creativecommons.org/licenses/by/4.0/). 